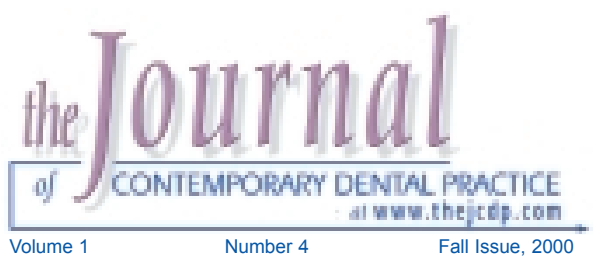

\title{
Effectiveness of Dentist-Prescribed, Home-Applied Tooth Whitening, A Meta-analysis
}

\author{
Richard Niederman, DMD, MS; Maggie C. Tantraphol; \\ Patricia Slinin, DMD; Catherine Hayes, DMD, DMSc; Suzy Conway, MLS
}
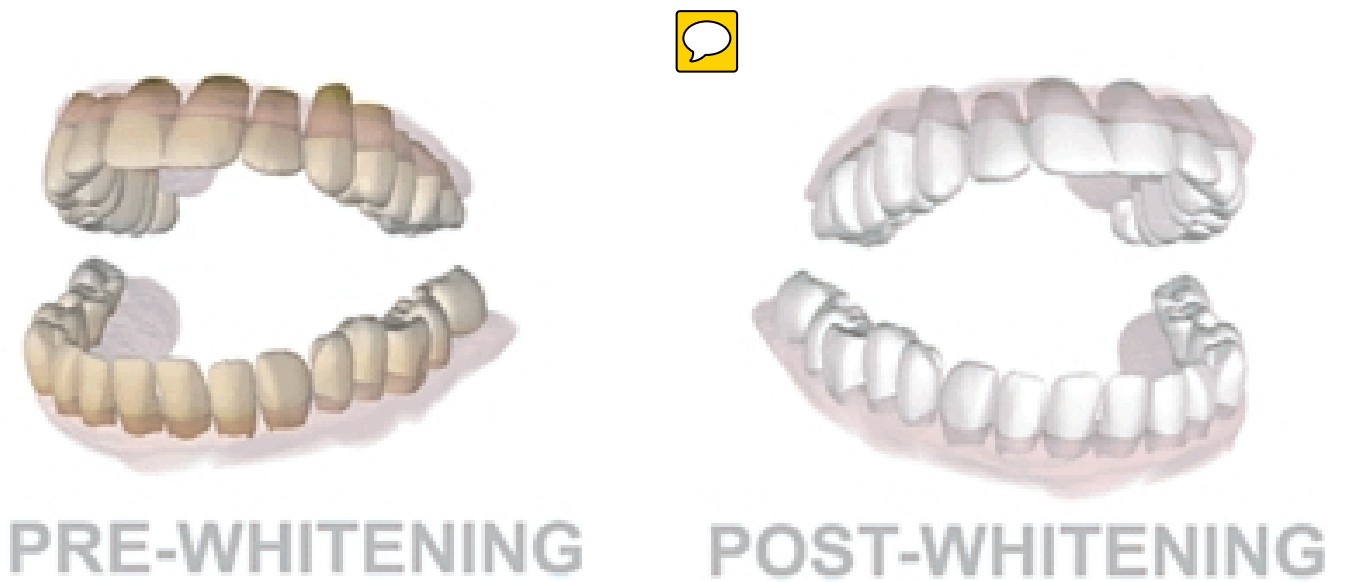

\section{Abstract}

Introduction. Common clinical experience suggests that tooth whitening agents are $100 \%$ effective. This study uses meta-analysis of data from published randomized controlled clinical trials to determine the efficacy of tooth whitening agents.

Methods. A MEDLINE search strategy was developed and implemented to systematically identify clinical trials on dentist-prescribed, home-applied tooth whitening agents, using 10\% carbamide peroxide, published between 1989-1999. Inclusion criteria (e.g., in English, human clinical trials) and exclusion criteria (e.g., not placebo controlled) were established and clinical trials that met these criteria were critically appraised for validity and clinical applicability. Meta-analysis was then used to quantitatively integrate the findings.

Results. Seven studies were identified that met the inclusion and validity criteria. These studies indicated that:

- Whitening results in a significant mean change of 64 shade guide units $(p<0.01)$, while the placebo control

group exhibited little change $(0.70 .6, p>0.05)$.

- $93 \%$ of the bleached patients exhibited 2 shade guide unit change, while $20 \%$ of the placebo control group exhibited this change.

- The brand of bleaching agent had a significant effect on tooth whitening,but the daily application time and duration of treatment did not.

- Whitening is maintained for 6 months for $1 / 2$ of the people treated.

- Neither gingival indices nor plaque indices were adversely or favorably affected by bleaching.

Clinical Applicability. The data from the reviewed studies indicate that rather than being $100 \%$ effective, on average:

- $73 \%$ (93\% for bleached group minus 20\% placebo group) of people who whiten their teeth will exhibit a

whitening that is 2 shade guide units greater than the placebo.

- $20 \%$ of the people who use dentist-prescribed, home-applied bleaching will achieve a mean whitening effect of 5 shade guide units.

- Re-treatment for $50 \%$ of people may be necessary to maintain this effect longer than 6 months.

- The methods used here are Internet applicable for other clinical topics.

Keywords: Tooth whitening, tooth bleaching, dental bleaching, tooth bleaching effectiveness 


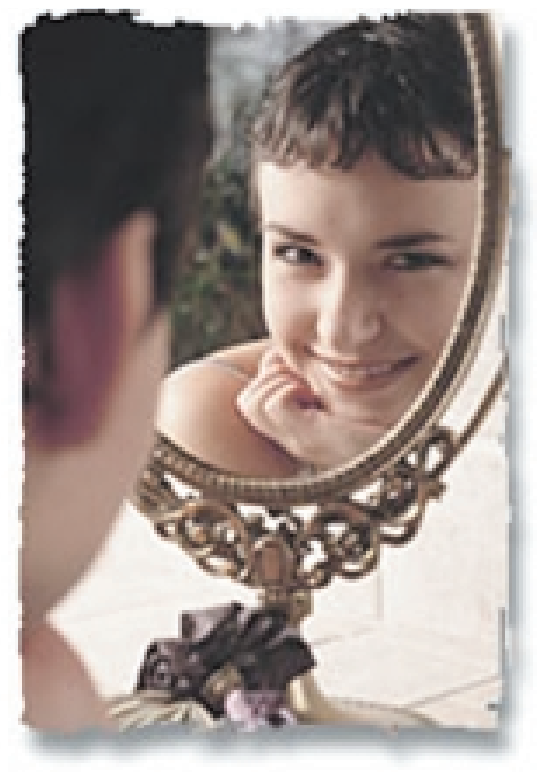

\section{Introduction}

Over the last decade, the demand for esthetic dentistry has grown tremendously as people seek to improve their smile. The introduction of the first paper on at-home tooth whitening by Haywood and Heymann ${ }^{1}$ in 1989 helped to revolutionize esthetic dentistry.

With the increasing popularity and rapid development of bleaching agents, questions also arose concerning their efficacy, longevity, and safety. Since 1989 over 600 articles on tooth bleaching have been published. Numerous studies suggest the effectiveness of dental products using $3 \%$ hydrogen peroxide $(10 \%$ carbamide peroxide) in whitening teeth. ${ }^{2,3}$ To achieve these benefits, bleaching agents are used for weeks at a time. Long-term use, however, increases the safety concerns that hydrogen peroxide containing agents may cause pulpal damage and/or gingival inflammation. ${ }^{4-5}$

The American Dental Association responded to these concerns by releasing "Guidelines for the Acceptance of Peroxide-Containing Oral Hygiene products"6 in 1994. According to these Guidelines, clinical efficacy may be demonstrated by a change of two value-oriented shade increments. A perceptible color change should be maintained in $50 \%$ of the recall population at 6 months as compared to the control to reflect duration of efficacy.
In this study, we systematically reviewed the published literature on dentist-prescribed, homeapplied tooth whitening agents to assess the efficacy and safety of this procedure. In particular we were interested in capturing this information in a quantitative way that can be conveyed to the patient.

\section{Materials and Methods \\ Information Retrieval}

A MEDLINE search strategy was developed to include the years 1989-1999 inclusive (Table 1), and implemented on the PubMed interface for MEDLINE at the US National Library of Medicine (http://www.ncbi.nlm.nih.gov/PubMed/). The search strategy was based on the recommendations of the US Agency for Health Care Policy and Research7 and the Centre for Evidence-based Medicine (http://cebm.jr2.ox.ac.uk/docs/levels.html) for establishing levels of evidence for quality.

Table 1. PubMed Search Strategy for Tooth Bleaching*

\begin{tabular}{|cl|}
\hline Step \# & \multicolumn{1}{c|}{ Term } \\
\hline 1 & Tooth Bleaching \\
2 & Limit 1 to English \\
3 & Limit 2 to human \\
4 & Limit 3 to randomized controlled trials \\
5 & Limit 4 to 1989 - 1999 \\
\hline
\end{tabular}

* The search can be rerun at the reader's convenience at PubMed in one of two ways:

1. Access PubMed at the Internet uniform resource locator:

http://www.ncbi.nlm.nih.gov/PubMed/ Then, copy and paste the following in the box "Search PubMed for ":

((()(“"tooth bleaching"[MeSH Terms] OR tooth bleaching[Text Word]) AND Randomized Controlled Trial[ptyp]) AND English[Lang]) AND notpubref[sb]) AND "human"[MeSH Terms]) AND (“1989”[PDat] : “2001”[PDat]))

2. Click on the Internet uniform resource locator (URL) on the following page, or copy and paste into the computer Internet URL box. 
http://www.ncbi.nlm.nih.gov:80/entrez/query.fc gi?cmd=PureSearch\&db=PubMed\&details_ter $\mathrm{m}=\% 28 \% 28 \% 28 \% 28 \% 28 \% 28 \% 22$ tooth $\% 20$ blea ching $\% 22 \% 5$ BMeSH\%20Terms\%5D\%20OR\%20 tooth\%20bleaching\%5BText\%20Word\%5D\%29 \%20AND\%20Randomized\%20Controlled\%20Tri al\%5Bptyp\%5D\%29\%20AND\%20English\%5BLa ng\%5D\%29\%20AND\%20notpubref\%5Bsb\%5D \%29\%20AND\%20\%22human\%22\%5BMeSH\%20 Terms\%5D\%29\%20AND\%20\%28\%221989\%22\% 5BPDat\%5D\%20\%3A\%20\%222001\%22\%5BPDa t\%5D\%29\%29

\section{Eligibility Criteria}

Identified studies were reviewed for exclusion/inclusion using the following criteria:
1. Clinical, not laboratory trial,

2. Placebo control,

3. $10 \%$ carbamide peroxide active ingredient,

4. Application using a custom-fitted tray,

5. Outcome variables reporting efficacy, or color whitening, using a change in shade guide units, and

6. Gingival and plaque indices to reflect safety.

Excluded randomized control articles are indicated in Table 2a and excluded clinical trials in Table $2 b$.

Table 2a. Excluded randomized controlled trials, and reason for exclusion

\begin{tabular}{|c|c|c|c|}
\hline Author & $\begin{array}{c}\text { In vivo } \\
\text { Human Trial }\end{array}$ & $\begin{array}{l}\text { Placebo } \\
\text { Control }\end{array}$ & $\begin{array}{c}\text { Patient } \\
\text { Applied } \\
\text { Tray }\end{array}$ \\
\hline Crim GA, 1992 & No & & \\
\hline Fischman SL, et al., 1992 & & & No \\
\hline Heymann, HO, et al., 1998 & No & & \\
\hline Hansen-Bayless, et al., 1992 & No & & \\
\hline Kowitz GM, et al., 1994 & & No & \\
\hline Kozlovsky A, et al., 1996 & & & No \\
\hline Kugel CM, et al., 1997 & & & No \\
\hline Matis, BA, et al., 1999 & & No & \\
\hline Miles PG, et al., 1994 & No & & \\
\hline Nathoo SA, et al., 1994 & & No & \\
\hline Schulte JR, et al., 1993 & & No & \\
\hline Schulte JR, et al., 1994 & & No & \\
\hline Whitman FJ, et al., 1995 & & & No \\
\hline
\end{tabular}


Table 2b. Excluded clinical trials, and reason for exclusion

\begin{tabular}{|l|c|c|c|c|c|}
\multicolumn{2}{|c}{$\begin{array}{c}10 \% \\
\text { Cauthor(s) } \\
\text { Peroxide }\end{array}$} & \multicolumn{1}{c}{$\begin{array}{c}\text { Placebo } \\
\text { Control }\end{array}$} & $\begin{array}{c}\text { Tetracycline } \\
\text { Stained } \\
\text { Teeth }\end{array}$ & $\begin{array}{c}\text { Patient } \\
\text { Applied } \\
\text { Tray }\end{array}$ & $\begin{array}{c}\text { Shade } \\
\text { Guide }\end{array}$ \\
\hline Lyons, 1998 & & No & & & \\
\hline Haywood, 1997 & & & & No & \\
\hline Swift, 1997 & & No & & & No \\
\hline Curtis, 1995 & & & & & \\
\hline Sterrett, 1995 & & No & & & No \\
\hline Haywood, 1994 & & No & & & No \\
\hline Small, 1994 & & & & & No \\
\hline Rustogi, 1994 & & & & & No \\
\hline Toh, 1993 & No & & & & \\
\hline Haywood, 1993 & & No & & & \\
\hline Gegauff, 1993 & & & & & \\
\hline Oueliet, 1992 & & & & & \\
\hline Rosenstiel, 1991 & & & & & \\
\hline
\end{tabular}

\section{Critical Appraisal}

To determine the validity of the identified studies, we employed the 7 criteria used on the Critical Appraisal Worksheets proposed by the Centre for
Evidence-based Medicine (http://cebm.jr2.ox.ac.uk/docs/teachingresources.h $\underline{\mathrm{tml}})^{8}$ (Table 3).

Table 3. Validity Assessment*

\begin{tabular}{|l|l|}
\hline \multicolumn{1}{|c|}{ Issue } & Yes/No \\
\hline 1. Was the assignment of patients to treatments randomized? & \\
2. Was the randomization list concealed? & \\
3. Were all patients who entered the trial accounted for at its conclusion? & \\
4. Were they analyzed in the groups to which they were randomized? & \\
5. Were patients and clinicians kept "blind" to which treatment was being & \\
& \\
received? & \\
6. Aside from the experimental treatment, were the groups treated equally? & \\
7. Were the groups similar at the start of the trial? & \\
\hline${ }^{*}$ http://cebm.jr2.ox.ac.uk/docs/teachingresources.html & \\
\hline
\end{tabular}


Articles meeting 5 out of 7 validity criteria were included (Table 4). The results of these studies were extracted for further analysis (Table 5).

Table 4. Validity Assessment, Included Articles

\begin{tabular}{|c|c|c|c|c|c|c|c|}
\hline \multirow[b]{2}{*}{ Author(s) } & \multicolumn{7}{|c|}{ Validity Criteria* } \\
\hline & 1 & 2 & $3^{* *}$ & 4 & $5^{* *}$ & 6 & 7 \\
\hline Curtis, et al., 1996 & Y & NS & Y (58/52) & $\mathrm{Y}$ & $Y(D)$ & $\mathrm{Y}$ & NS \\
\hline Howard, 1992 & Y & NS & $Y(37 / 32)$ & $\mathrm{Y}$ & $Y(D)$ & $\mathrm{Y}$ & NS \\
\hline Kowitz, et al., 1994 & $\mathrm{Y}$ & NS & $\mathrm{Y}(75 / 70)$ & $Y$ & $Y(D)$ & $\mathrm{N}$ & NS \\
\hline Matis, et al., 1998 & Y & $\mathrm{Y}$ & $Y(60 / 60)$ & $\mathrm{Y}$ & $Y(D)$ & $\mathrm{Y}$ & $\mathrm{Y}$ \\
\hline Reinhardt, et al., 1993 & $\mathrm{Y}$ & NS & $Y(56 / 56)$ & $\mathrm{Y}$ & $Y(D)$ & $\mathrm{Y}$ & NS \\
\hline Rosentiel, et al., 1996 & Y & NS & $\mathrm{Y}(52 / ?)$ & $\mathrm{Y}$ & $Y(D)$ & $\mathrm{Y}$ & Y \\
\hline Russell, et al., 1996 & Y & Y & $Y(50 / 50)$ & $\mathrm{Y}$ & $Y(D)$ & $\mathrm{Y}$ & $Y$ \\
\hline $\begin{array}{ll}* & Y=Y e s ; N=N o ; N S \\
* * & \text { \# Subjects at star } \\
* * * & D=\text { double blind; S }\end{array}$ & & jatec & end & & & & \\
\hline
\end{tabular}

Table 5. Studies and variables included in the meta-analysis

\begin{tabular}{|c|c|c|c|c|c|c|c|c|c|}
\hline \multirow[b]{2}{*}{ Author(s) } & \multirow{2}{*}{$\begin{array}{l}\text { Bleaching } \\
\text { Products } \\
\text { (Brand) }^{\star *}\end{array}$} & \multicolumn{4}{|c|}{ Sample Size } & \multirow{2}{*}{$\begin{array}{l}\text { Treatment } \\
\text { (time/day) }\end{array}$} & \multirow{2}{*}{$\begin{array}{l}\text { Time } \\
\text { (days) }\end{array}$} & \multirow{2}{*}{$\begin{array}{l}\text { Follow-up } \\
\text { (weeks) }\end{array}$} & \multirow{2}{*}{$\begin{array}{l}\text { Outcome } \\
\text { Variable(s) }\end{array}$} \\
\hline & & Ct & $\begin{array}{c}\text { Exp } \\
1\end{array}$ & $\begin{array}{c}\operatorname{Exp} \\
2\end{array}$ & $\begin{array}{c}\text { Exp } \\
3\end{array}$ & & & & \\
\hline Curtis, et al., 1996 & 5 & \multicolumn{2}{|c|}{3030} & $\mathrm{~N} / \mathrm{A}$ & $N / A$ & Overnight & $>14$ & $1,2,6$ & \\
\hline Howard, 1992 & 1,2 & 8 & 12 & 12 & $\mathrm{~N} / \mathrm{A}$ & $<4$ hr/day & $<7$ & 6 & $\begin{array}{l}\text { Gingival Index, } \\
\text { Plaque Index }\end{array}$ \\
\hline Kowitz, et al., 1994 & 2,4 & 22 & 24 & 24 & N/A & $<4$ hr/day & $>14$ & 1,2 & Shade Guide \\
\hline Matis, et al, 1998 & 5 & 303 & & $\mathrm{~N} / \mathrm{A}$ & N/A & Overnight & $>14$ & $\begin{array}{c}1,2,3,6 \\
12,24\end{array}$ & Shade Guide \\
\hline Reinhardt, et al, 1993 & $1,2,3$ & 16 & 15 & 17 & 16 & $\begin{array}{l}<4 \mathrm{hr} / \mathrm{day}, \\
\text { Overnight }\end{array}$ & $>14$ & 3 & $\begin{array}{l}\text { Shade Guide, } \\
\text { Gingival Index, } \\
\text { Plaque Index }\end{array}$ \\
\hline Rosentiel, et al, 1996 & 5 & 26 & 26 & $\mathrm{~N} / \mathrm{A}$ & N/A & Overnight & $<7$ & $\begin{array}{l}1,3,6 \\
12,24\end{array}$ & Gingival Index \\
\hline Russell, et al, 1996 & 5 & 26 & 24 & $\mathrm{~N} / \mathrm{A}$ & N/A & Overnight & $>14$ & $\begin{array}{l}1,2,6 \\
12,24\end{array}$ & Shade Guide \\
\hline \multicolumn{10}{|c|}{$\begin{aligned} * \quad \# & =\text { number of patients, Ct }=\text { control group }, \\
\text { ** } & =\text { White \& Brite, Omni International } \\
2 & =\text { Rembrandt Lighten, Den-Mat } \\
3 & =\text { Proxigel, Reed and McCormick } \\
4 & =\text { Colgate Platinum, Colgate Palmolive } \\
5 & =\text { Opalesence, Ultradent Products, Inc. }\end{aligned}$} \\
\hline
\end{tabular}




\section{Statistical Methods}

We evaluated shade guide unit change to reflect efficacy and both gingival and plaque indices to reflect safety. All three were analyzed for the significance of four variables: treatment group, daily application time, the duration of treatment, and brand of bleach (Table 6).

Table 6. Overview of Meta-analysis Variables

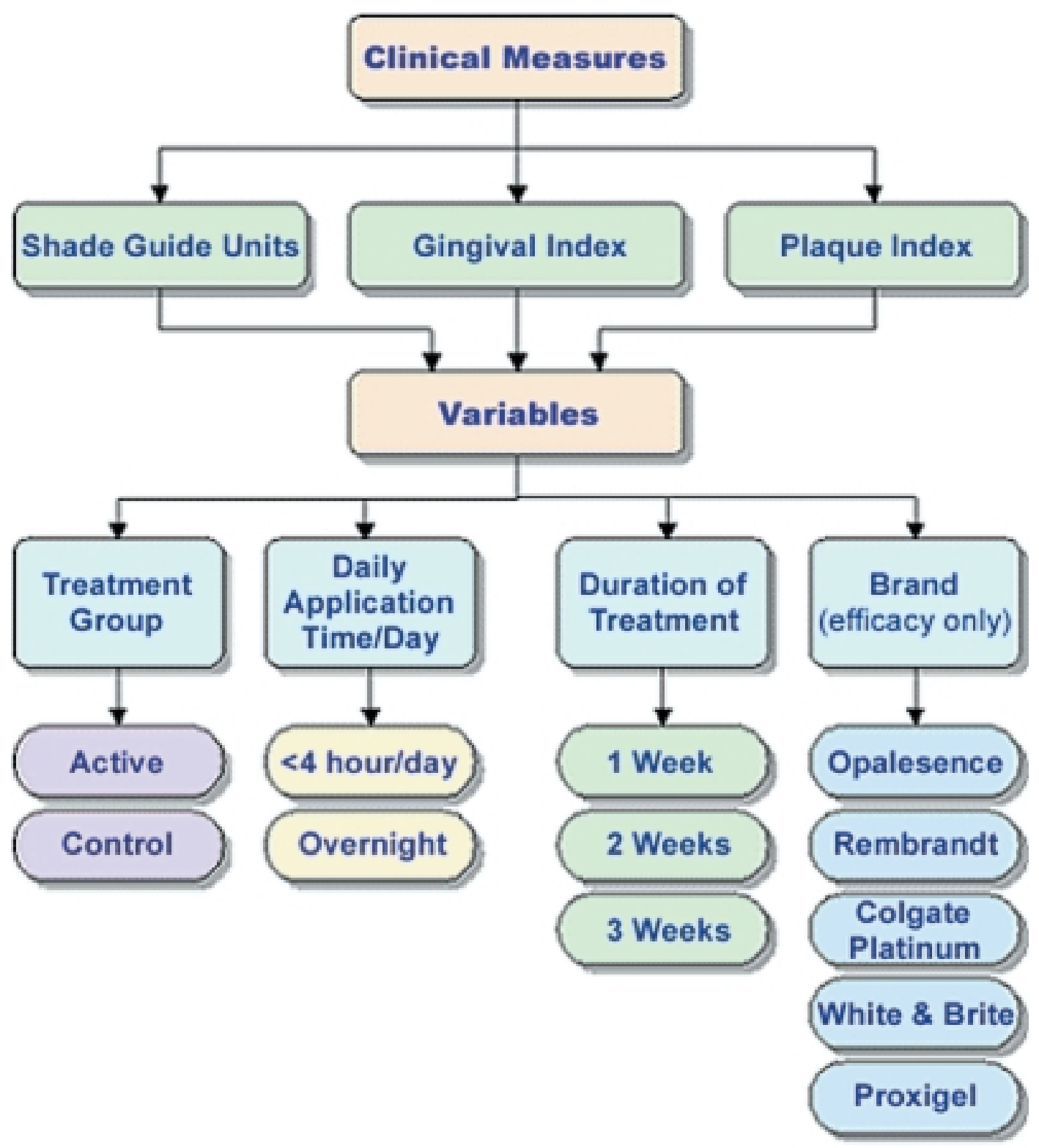


Using the computer program SPSS, the treatment groups and daily application time were analyzed using the t-test (Table $7 a, b)$.

Analysis of variance (ANOVA) was performed to isolate differences in effectiveness between the 3 different duration of treatment lengths (1, 2, and 3 weeks, Table 7c) as well as between the
5 different brands of bleaching agents used (Table 7d).

To determine the size and potential benefit of tooth bleaching from a patient-centered perspective, we calculated the $\%$ of patients affected and the mean number needed to treat (NNT) (Table 8) http://cebm.j2.ox.ac.uk/docs/nnt.html).

Table 7a. Mean change in shade guide units

\begin{tabular}{|c|c|c|c|c|c|c|c|}
\hline Variable & Group & Mean & SD* & $\mathbf{N}^{* *}$ & Min & Max & p-value \\
\hline \multirow{2}{*}{$\begin{array}{l}\text { Treatment } \\
\text { Group }\end{array}$} & Active & 5.9 & 4.094 & & 0.4 & 17.5 & \multirow{2}{*}{$<0.01$} \\
\hline & Control & 0.7 & 0.6 & 174 & 0 & 1.5 & \\
\hline
\end{tabular}

Table $7 \mathrm{~b}$. Mean change in shade guide units by treatment time

\begin{tabular}{|c|c|c|c|c|c|c|c|}
\hline Variable & Group & Mean & SD* & $\mathbf{N}^{* *}$ & Min & Max & $p$-value \\
\hline \multirow{2}{*}{$\begin{array}{l}\text { Daily } \\
\text { Application } \\
\text { Time }\end{array}$} & $<4 \mathrm{hr} /$ day & 4.6 & 2.1 & 97 & 0.4 & 7.1 & \multirow[b]{2}{*}{$>0.2$} \\
\hline & Overnight & 7.8 & 5.5 & 77 & 4.5 & 17.5 & \\
\hline
\end{tabular}

Table 7c. Mean change in shade guide units by treatment duration

\begin{tabular}{|l|c|c|c|c|c|c|c|}
\hline Variable & \multicolumn{2}{c}{ Group } & Mean & SD* $^{*}$ & \multicolumn{2}{c|}{$\mathbf{N}^{* *}$} & \multicolumn{2}{c|}{ Min } & \multicolumn{2}{c|}{ Max } & p-value \\
\hline Duration & 1 week & 4.9 & 1.6 & 24 & 3.7 & 6 & \\
\cline { 2 - 8 } $\begin{array}{c}\text { of } \\
\text { Treatment }\end{array}$ & 2 weeks & 8.7 & 5.9 & 102 & 5.1 & 17.5 & \multirow{2}{*}{$>0.2$} \\
\cline { 2 - 8 } & 3 weeks & 4.4 & 2.2 & 48 & 0.4 & 6.9 & \\
\hline
\end{tabular}

Table 7d. Mean change in shade guide units by bleach brand

\begin{tabular}{|c|c|c|c|c|c|c|c|}
\hline Variable & Group & Mean & SD* & $\mathbf{N}^{* *}$ & Min & Max & p-value \\
\hline \multirow{5}{*}{$\begin{array}{l}\text { Brand } \\
\text { of } \\
\text { Bleach }\end{array}$} & Opalesence & 11.4 & 8.6 & 54 & 5.3 & 17.5 & \multirow{5}{*}{$<0.01$} \\
\hline & $\begin{array}{l}\text { Colgate } \\
\text { Platinum }\end{array}$ & 7.1 & NA & 24 & NA & NA & \\
\hline & Rembrandt & 5.3 & 1.3 & 52 & 3.7 & 6.9 & \\
\hline & Proxigel & 4.7 & 0.21 & 17 & 4.6 & 4.9 & \\
\hline & White \& Brite & 3.6 & 2.1 & 27 & 0.4 & 6 & \\
\hline
\end{tabular}

* Standard Deviation, ${ }^{* *} \mathrm{~N}=$ Number of Subjects 
Table 8. Number needed to treat to achieve 2 shade increment benefit

\begin{tabular}{|c|c|c|c|c|c|}
\hline Author & Product & $\begin{array}{c}\text { Control } \\
\text { Event Rate } \\
\text { CER }\end{array}$ & $\begin{array}{c}\text { Experimental } \\
\text { Event Rate } \\
\text { EER }\end{array}$ & $\begin{array}{c}\text { Absolute } \\
\text { Benefit } \\
\text { Increase } \\
\text { (EER-CER)= } \\
\text { ABI }\end{array}$ & $\begin{array}{c}\text { Number } \\
\text { Needed } \\
\text { to Treat } \\
(1 / \mathrm{ABI}) \times 100= \\
\text { NNT }\end{array}$ \\
\hline Kowitz et al, 1994 & Rembrandt & $22.7 \%$ & $90.9 \%$ & $68.2 \%$ & 1.5 \\
\hline Kowitz et al, 1994 & Colgate & $22.7 \%$ & $100 \%$ & $77.3 \%$ & 1.3 \\
\hline Russell et al, 1996 & Opalesence & $15.4 \%$ & $87.5 \%$ & $72.1 \%$ & 1.4 \\
\hline
\end{tabular}

Because all people do not respond similarly, NNT provides a patient centered outcome estimate. The NNT identifies how many people need to be treated for one patient to obtain a significant benefit when compared to the control. We determined an observable benefit in two ways:

1. a two-increment change in shade guide units and

2. a mean change in total shade guide units.

\section{Results}

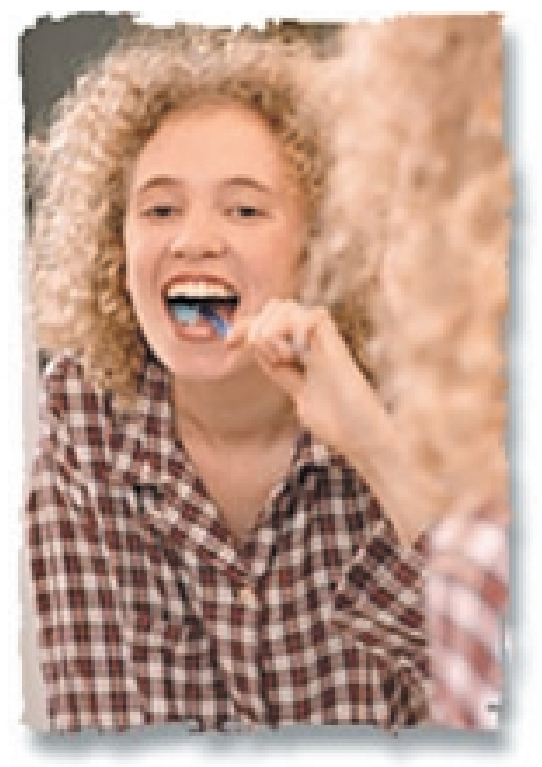

The MEDLINE search (Table 1) identified 28 randomized controlled trials evaluating tooth bleaching. Of these, 20 examined dentistprescribed, patient applied tooth whitening agents. Of

the 20,13 did not meet additional inclusion criteria (Table 2). The 7 remaining studies were critically appraised and met validity criteria (Tables $3,4)$.

\section{Critical Appraisal of Clinic Importance}

Of the 7 studies, 5 studies evaluated efficacy using shade guide units, while 3 examined gingival index and or plaque index (Table 5). The data in these studies indicated that dentistprescribed, home-applied agents using a $10 \%$ carbamide peroxide gel delivered in a customfitted tray whitened teeth significantly, when compared to a placebo control group (Figure1 Table $7 \mathrm{a}$ ). The bleached group had a significant mean change of $5.9(S D= \pm 4)$ shade guide units out of a possible 24 ( $24 \%$ change; $p<0.01)$, while the control group had a mean change of 0.7 $(S D= \pm 0.6)$ shade guide units $(3 \%$ change; $p>$ 0.05).

Neither daily application time nor duration of treatment had a significant effect on the change in mean shade guide units (Table 7b, 7c). Daily application time was categorized into two groups who wore bleaching trays either (1) less than 4 hours/day or (2) overnight. Mean changes in shade guide units changes were $4.6(\mathrm{SD}= \pm 2.1)$ and $7.8(\mathrm{SD}= \pm 5.5)$, respectively. While the change was greater with longer wear, the statistical difference was not significant (Table $7 \mathrm{~b}$, p > 0.2).

Duration of treatment ranged from one to three weeks. Mean changes in shade guide units were $4.9(\mathrm{SD}= \pm 1.6), 8.8(\mathrm{SD}= \pm 5.9)$, and $4.4(\mathrm{SD}=$ \pm 2.2 ) for 1 week, 2 weeks, and 3 week long treatments, respectively. Despite the extended exposure time to the active bleaching ingredient, no statistical differences were noted (Table 7c, $p$ $>0.2$ ).

Lastly, in determining efficacy, the five brands of bleaching agents were compared for effect on the mean change in shade guide units (Figure 2 Table 7d). Opalescence produced a significantly 
greater mean change in shade guide units than three of the other brands (mean $=11.48 .6, p=$ 0.01 ). The 4 th brand was not included in this comparison since the reported data were insufficient for analysis.

\section{Clinical Applicability}

To quantify the bleaching experience from a patient's perspective, we calculated the \% of people that would achieve the indicated results and from that a number needed to treat (NNT). That is, the number of people that would need to be treated for one person to show a whitening that was significantly greater than the control group. This calculation was done for two outcome variables: (1) percentage of people with a two-increment change in shade guide units and (2) mean shade guide change.

The percentage of people who will achieve 2 shade guide unit change, when compared to the control group was 73\% (Table 8).
This translates to an NNT of 1.4. Stated another way, 1.4 people will be treated for 1 to achieve a 2-unit shade guide change that is greater than the control. After rounding, this is equivalent to approximately 2 out of 3 people (i.e., $66 \% 73 \%$ ).

Using similar methods, the percent of people who will achieve a shade guide change of 5 units greater than the control is $20 \%$. This translates to an NNT of 5 . Thus, for every 5 people treated, 1 will achieve a shade guide change of 5 units greater than the control.

Finally, using similar methods, at 6 months 50\% of the people who achieved a shade guide change of 2 maintained that shade guide change, while the other $50 \%$ did not.

\section{Safety}

To assess the safety of $10 \%$ carbamide peroxide gel, the identified studies examined plaque accumulation and gingival inflammation. For the plaque index $(\mathrm{PI})$, there were no significant differences between the bleached and control groups PI (Table 9, all $p>0.3$ ).

Table 9. Mean change in plaque indices

\begin{tabular}{|c|c|c|c|c|c|c|c|}
\hline Variable & Group & Mean & SD* & $\mathbf{N}^{* *}$ & Min & Max & p-value \\
\hline \multirow{2}{*}{$\begin{array}{l}\text { Treatment } \\
\text { Group }\end{array}$} & Active & 0.45 & 0.28 & 73 & 0.1 & 0.8 & \multirow{2}{*}{0.5} \\
\hline & Control & 0.29 & 0.44 & 35 & 0 & 0.8 & \\
\hline \multirow{2}{*}{$\begin{array}{l}\text { Daily } \\
\text { Application } \\
\text { Time }\end{array}$} & $<4 \mathrm{hr} /$ day & 0.47 & 0.35 & 25 & 0.2 & 0.8 & \multirow[b]{2}{*}{0.9} \\
\hline & Overnight & 0.43 & 0.28 & 48 & 0.1 & 0.8 & \\
\hline \multirow{2}{*}{$\begin{array}{l}\text { Duration of } \\
\text { Treatment }\end{array}$} & 2 weeks & 0.12 & 0 & 25 & 0.1 & 0.1 & \multirow{2}{*}{0.3} \\
\hline & 3 weeks & 0.5 & 0.27 & 48 & 0.1 & 0.8 & \\
\hline
\end{tabular}


Table 10. Mean change in gingival indices

\begin{tabular}{|c|c|c|c|c|c|c|c|}
\hline Variable & Group & Mean & SD* & $\mathbf{N}^{* *}$ & Min & Max & p-value \\
\hline \multirow{2}{*}{$\begin{array}{l}\text { Treatment } \\
\text { Group }\end{array}$} & Active & 0.25 & 0.15 & 129 & 0 & 0.5 & \multirow[b]{2}{*}{0.3} \\
\hline & Control & 0.16 & 0.15 & 64 & 0 & 0.4 & \\
\hline \multirow{2}{*}{$\begin{array}{l}\text { Daily } \\
\text { Application } \\
\text { Time }\end{array}$} & $<4$ hr/day & 0.23 & 0.21 & 25 & 0 & 0.4 & \multirow[b]{2}{*}{0.8} \\
\hline & Overnight & 0.26 & 0.13 & 104 & 0.08 & 0.5 & \\
\hline \multirow{3}{*}{$\begin{array}{l}\text { Duration of } \\
\text { Treatment }\end{array}$} & 1 week & 0.3 & $\mathrm{n} / \mathrm{a}$ & 26 & 0.3 & 0.3 & \multirow{3}{*}{0.9} \\
\hline & 2 weeks & 0.28 & 0.28 & 55 & 0.09 & 0.5 & \\
\hline & 3 weeks & 0.23 & 0.14 & 48 & 0 & 0.4 & \\
\hline
\end{tabular}

Three studies determined the difference in gingival index $(\mathrm{Gl})$ between baseline and the end of treatment (Table 10).

There were no significant differences between the bleached and control group's GI for the three treatment differences: treatment group, daily application time, and duration of treatment on the mean change of $\mathrm{Gl}$ (all $p>0.3$ ).

\section{Discussion}

This study was conducted to determine the efficacy of tooth whitening agents and quantify the whitening from a patient's perspective using a meta-analysis of data from published human clinical trials.

According to the ADA's "Guidelines for the Acceptance of Peroxide-Containing Oral Hygiene products" 6 four outcomes are recommended to evaluate tooth bleaching efficacy: shade guide, photography, colorimetry, and computer digitization. Only one of the identified studies reported photography results 22 and none used computer digitization. Although a computerized colorimeter is objective and eliminates the potential for human bias and variability 3 , its clinical relevance is unclear.

The meta-analysis of the published clinical trials indicate that, in the patient populations examined, and for the whitening agents examined, tooth whitening is effective and it neither adversely or favorably affects the gingiva or plaque. There are, however, several refinements to this statement. First, contrary to expectation, $73 \%$, not $100 \%$ of the patients who undergo tooth whitening, can expect a shade guide change of 2 units. Second, $20 \%$ of patients can expect a 5 shade guide unit change. Finally, the current formulations of carbamide peroxide gel are not equally effective, thus some products are more significantly more efficacious than others are.

The complexities of these subtleties are, perhaps, best understood in the context of Figure 1.

\section{Figure 1.}

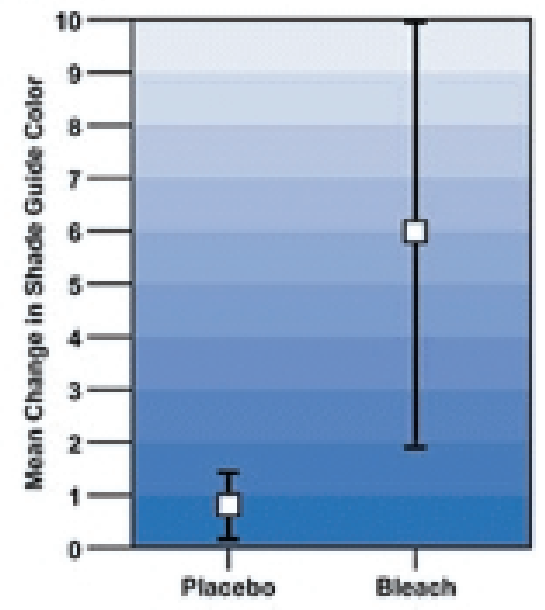

Comparison of placebo gel and bleaching gel in effecting tooth color change. The square indicates the mean change in shade guide color. The vertical bars indicate the standard deviation.

Figure 1 indicates the mean change in shade guide units is $\sim 5$. If this were interpreted as the occurrence in most patients, a clinician might suggest, inaccurately, that "on average a patient can expect a 5 shade guide unit change." In fact, the data when calculated as the NNT suggest 
less than half this effect, as indicated in the previous paragraph. For patient communication, the NNT thus offers an alternate, more nuanced method for managing a patient's expectation of care outcomes. On the other hand, it is also clear there are significant differences in product performance (Figure 2).
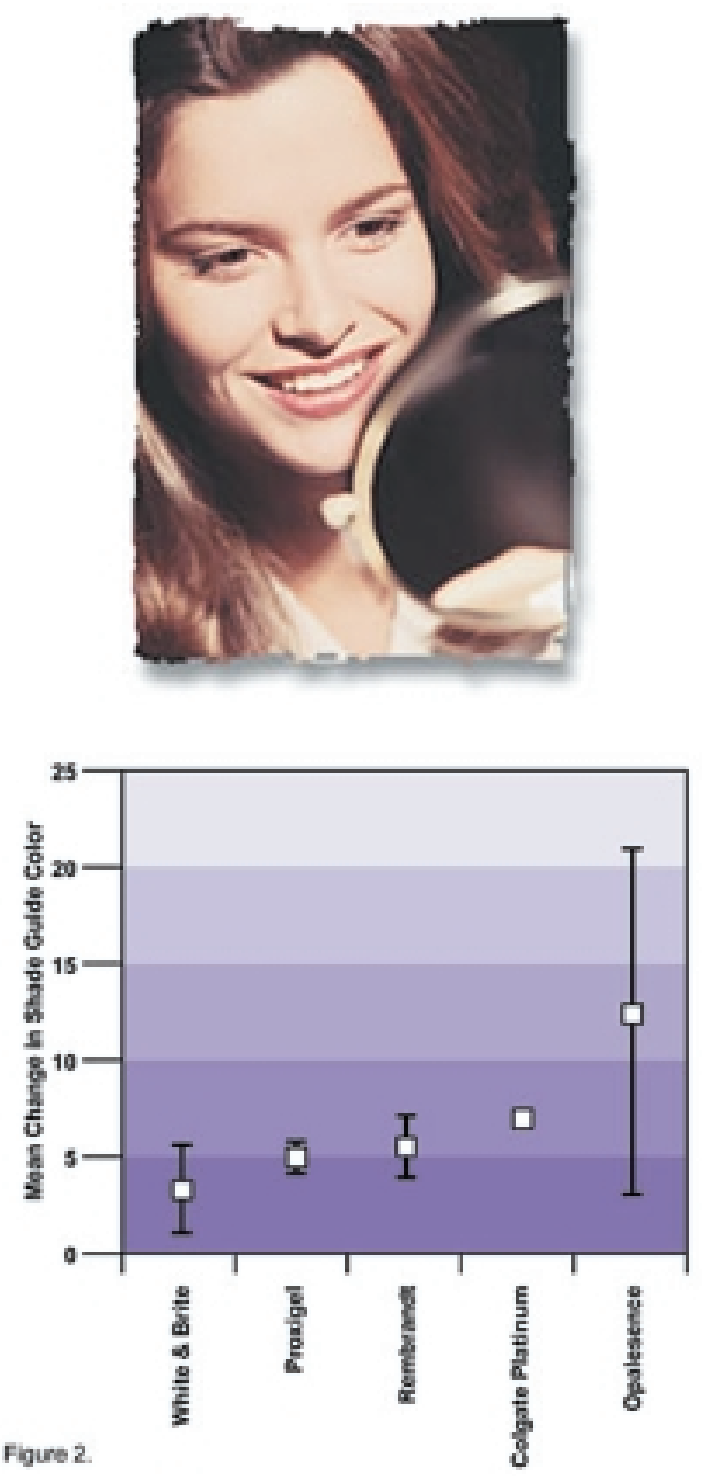

Comparison of 5 different bleaching gels in effecting tooth color change. The square indicates the mean change in shade guide color. The vertical bars indicate the standard deviation.

This can also be used in guiding product selection and recommendations.

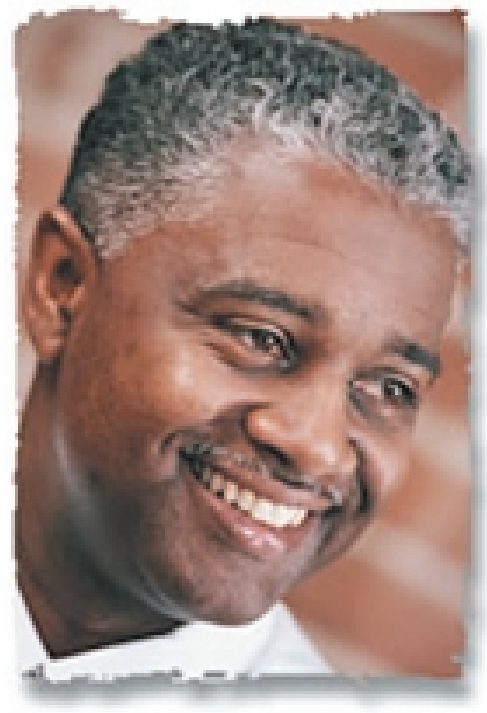

Another aspect of this study was the use of the Internet to carry out the initial elements of the review. These elements point toward newer methods of clinical information access and retrieval. With open access to PubMed (http://www.ncbi.nlm.nih.gov/PubMed/), clinicians can now routinely and inexpensively run clinical searches to obtain the most current information. Using PubMed's "Limits" function, as used in this study stratifies the level of evidence. Alternatively the use of PubMed's "Clinical Queries" (http://www.ncbi.nlm.nih.gov:80/entrez/query/static /clinical.html) allows one to prepare sensitive or specific clinical searches on etiology, diagnosis, therapy, or prognosis. Finally, the PubMed's "cubbys"

(http://www.ncbi.nlm.nih.gov:80/entrez/cubby/login .fcgi?call=so.SignOn..Login) provide a mechanism for both saving and retrieving searches. Saved searches can then be re-run to update the information ad libitum. Accessing information beyond the title and abstract are also facilitated by PubMed. Articles that are not available in a personal or local library can be ordered through PubMed's "Loansome Doc" service

(http://tendon.nlm.nih.gov/ld/loansome.html). This approach to accessing key clinical information offers one a low cost, low barrier mechanism for clinical updating. 


\section{Discussion}

Several caveats regarding the results also need to be addressed. First, the identified studies utilized two shade guide systems: Trubyte Bioform (Densply/York Division) and the Vita shade guide (Lumin Vacuum Shade Guide, Via Zahnfabrik, H. Rauter GmbH \& Co. KG, Sackingen, Germany) for shade matching. Utilizing a shade guide system to measure efficacy has the following limitations:

1. There is no shade guide standard.

2. The shade guide units are not evenly distributed in color space and are not as discriminating as the measured colorimeter parameters. $^{3}$

3. Color matching using a shade guide is subject to clinician variability and bias.

Despite these limitations, measuring color change with a shade guide remains the most clinically relevant patient-centered outcome measure. To accommodate for these different standards, changes were noted as $\%$ change and NNT calculated.A second caveat is the limiting of this systematic review to randomized controlled trials identified on MEDLINE, published in English. The disadvantages of these choices are they eliminate from consideration clinical trials that are cohort, case-control, and/or case series. They also eliminate articles that might appear in other databases (e.g., EMBASE, Cochrane) but not MEDLINE, and in other languages. The advantage, however, is that randomized controlled trials provide the strongest level of evidence, ${ }^{7,8}$

(http://cebm.jr2.ox.ac.uk/docs/levels.html), MEDLINE is the world's largest free access medical literature database, and the cited articles will be largely available to an English speaking audience Third, the review does not address publication bias. That is, those articles that are not published because they did not show clinical efficacy cannot be evaluated. Thus, this review itself is biased, in that it may overestimate clinical efficacy.In summary, given several caveats, the results indicate that, on average, dentistprescribed, home-applied tooth whitening will whiten teeth and neither adversely or beneficially affect the gingiva or plaque.

\section{Case Studies}

\section{Case 1. Tooth Whitening}

A 40-year-old female presented with a chief complaint: "I want my teeth whitened." The patient's pretreatment shade was A4 (left). After 2 weeks of bleaching a shade of B1 was achieved (right).

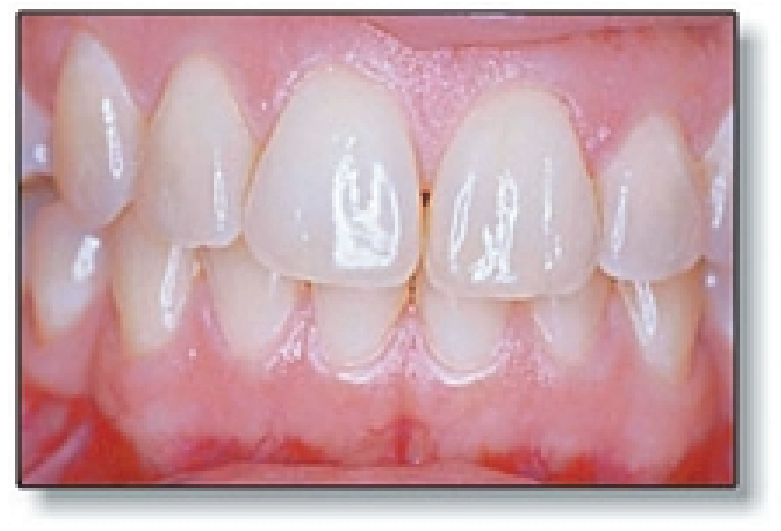

Figure 1a. Before bleaching.

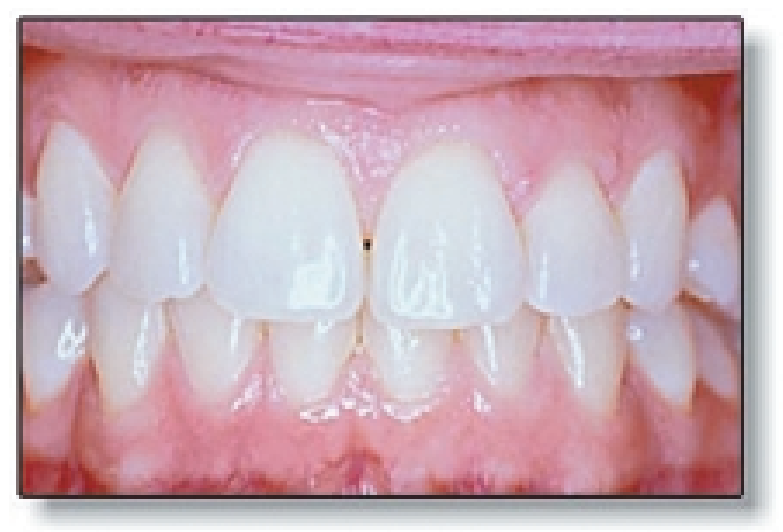

Figure 1b. After bleaching. 


\section{Case 2. Tooth Whitening + Removable Partial} Denture

A 51-year-old Hispanic female presented with a chief complaint of an ill-fitting maxillary removable partial denture (RPD) that was several years old. The patient was also unhappy with the esthetics and color (left). In conjunction with RPD fabrication, bleaching was prescribed (right).

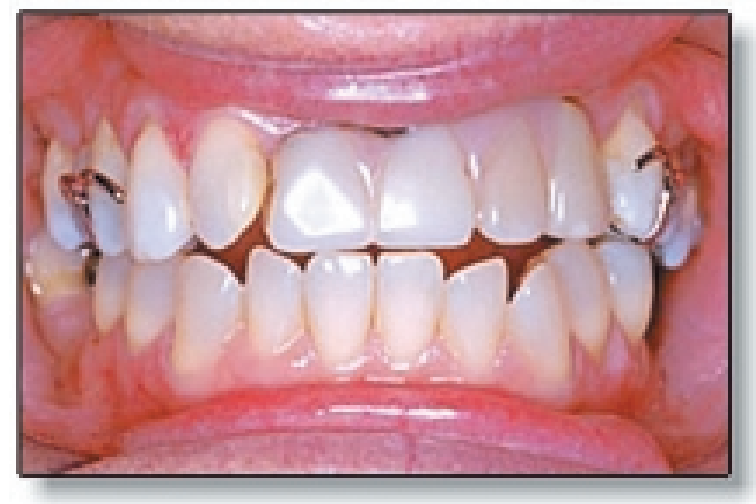

Figure 2a. Before bleaching.

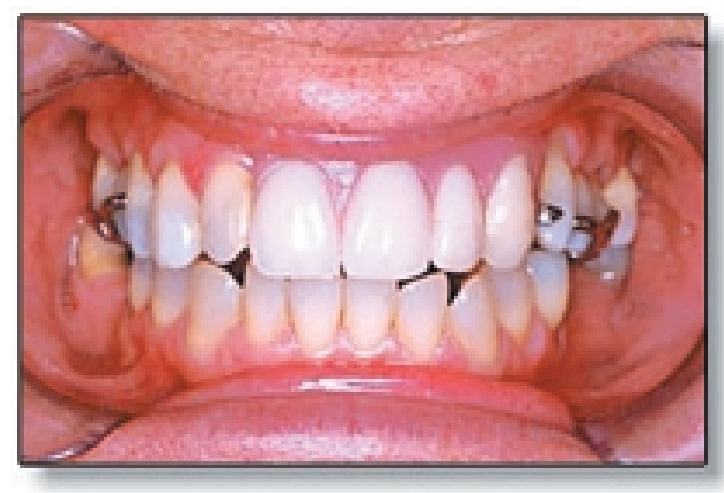

Figure 2b. After bleaching.

\section{Case 3. Tooth Whitening + All Ceramic \\ Crowns}

A 49-year-old female presented with a chief complaint of unesthetic maxillary lateral incisor porcelain fused to metal crowns. The patient reported having the crowns fabricated 15 years previously to cover "peg laterals." Her teeth were now much darker (A3) than her crowns, and metal margins were exposed on the crowns (left). Treatment included tooth whitening, gingival recontouring, and new all-ceramic crowns to match the new tooth shade (C1) (right).

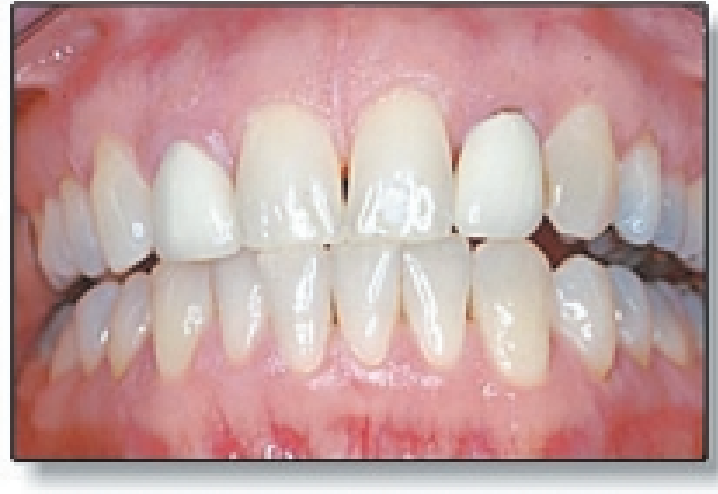

Figure 3a. Before treatment.

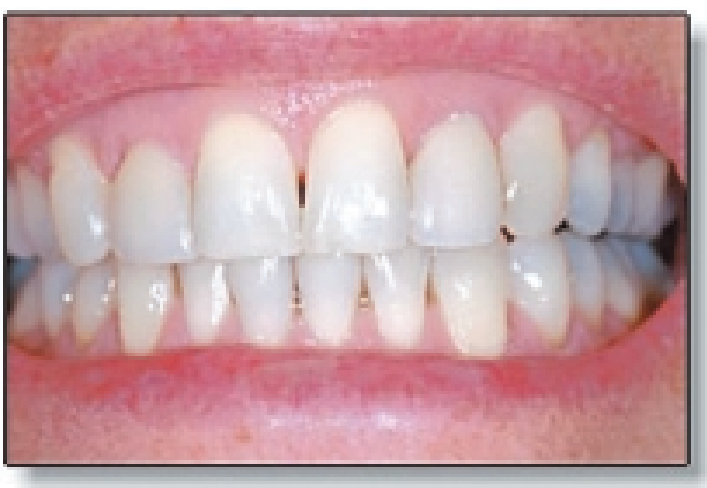

Figure 3b. After treatment. 


\section{References}

1. Haywood VB, Heymann HO. Nightguard vital bleaching. Quintessence Int 1989;20(3): 173-6.

2. Haywood VB, Leonard RH, Nelson CF, Brunson WD. Effectiveness, side effects, and long-term status of nightguard vital bleaching. J Am Dent Assoc 1994;125: 1219-1226.

3. Gegauff AG, Rosenstiel SF, Langhout KJ, Johnston WM. Evaluating tooth color change from carbamide peroxide gel. J Am Dent Assoc 1993;134: 65-72.

4. Robertson WD, Melfi RC. Pulpal response to vital bleaching procedures. J Endod 1980;6: 645-9.

5. Cohen SC. Human pulpal response to bleaching procedures on vital teeth. J Endod 1979;5: 134-8.

6. Council on Dental Therapeutics. Guidelines for the acceptance of peroxide-containing oral hygiene products. J Am Dent Assoc 1994;125: 1140-1142.

7. Levine R, Shaneman R. An evidence-based treatment approach: Translating clinical outcomes to patient value. Int J Periodontics Restorative Dent 1998;3: 327-38.

8. Sackett DL, Richardson WS, Rosenberg W, Haynes RB. Evidence-based medicine. How to practice and teach EBM. New York: Churchill Libingsone, 1997.

9. Crim GA. Post-operative bleaching: effect on microleakage. Am J Dent 1992;5(2): 109-12.

10. Hansen-Bayless J, Davis R. Sealing ability of two intermediate restorative materials in bleached teeth. Am J Dent 1992;5(3): 141-4.

11. Miles PG, Pontier JP, Bahiraei D, Close J. The effect of carbamide peroxide bleach on the tensile bond strength of ceramic brackets: an in vitro study. Am J Orthod Dentofacial Orthop. 1994;106(4): 371-5.

12. Heymann HO, Swift EJ Jr., Bayne SC, May KN Jr., Wilder AD Jr., Mann GB, Peterson CA. Clinical evaluation of two carbamide peroxide tooth-whitening agents. Compend Contin Educ Dent 1998;19(4): 359-62, 364-6, 369.

13. Kowitz GM, Nathoo SA, Wong R. Comparative clinical evaluation of two professional tooth-whitening products. Compendium 1994; Suppl 17: S635-9.

14. Nathoo SA, Chmielewski MB, Rustogi KN. Clinical evaluation of Colgate Platinum Professional Toothwhitening System and Rembrandt Lighten Bleaching Gel. Compendium 1994; Suppl 17: S640-5.

15. Schulte JR, Morrissette DB, Gasior EJ, Czajewski MV. Clinical changes in the gingiva as a result of at-home bleaching. Compendium1993;14(11) 1362, 1364-6.

16. Schulte JR, Morrissette DB, Gsior EJ, Czajewski MV. The effects of bleaching application time on the dental pulp. J Am Dent Assoc 1994;125(10): 1330-5.

17. Matis BA, et.al. In vivo degradation of bleaching gel used in whitening teeth. J Am Dent Assoc 1999 Feb;130(2): 227-35.

18. Fischman SL, Truelove RB, Hart R, Cancro LP. The laboratory and clinical safety evaluation of a dentrifice containing hydrogen peroxide and baking soda. J Clin Dent. 1992;3(4): 104-10.

19. Kozlovsky A, Sintov A, Artzi Z, Tal H. Clinical efficacy of a degradable film-forming product containing carbamide peroxide to reduce tooth discolouration. Oral Health 1996; 86(3): 47-9.

20. Kugel G, Perry RD, Hoang E, Scherer W. Effective tooth bleaching in 5 days: using a combined inoffice and at-home bleaching system. Compend Contin Educ Dent 1997; 18(4): 378, 380-3.

21. Whitman FJ, Simon JF. A clinical comparison of two bleaching systems. J Calif Dent Assoc. 1995;23(12): 59-64.

22. Matis BA, Cochran MA, Eckert G, Caroson TJ. The efficacy and safety of a $10 \%$ carbamide peroxide bleaching gel. Quintessence Int 1998;29(9): 555-63.

23. Rosenstiel SF, Gegauff AG, Johnston WM. Randomized clinical trial of the efficacy and safety of a home bleaching procedure. Quintessence Int 1996;27(6): 413-24.

24. Russell CM, Dickinson GL, Johnson MH, Curtis JW Jr., Downey MC, Haywood VB, Myers ML. Dentist-supervised home bleaching with ten percent carbamide peroxide gel: a six-month study. J Esthet Dent 1996;8(4): 177-82.

25. Kowitz Gm, Nathoo SA, Rustogi KN, Chmielewski MB, Liang LJ, Wong R. Clinical comparison of Colgate Platinum Toothwhitening System and Rembrandt Gel Plus. Compendium 1994; Suppl 17: S646-51.

26. Reinhardt JW, Elvins SE, Swift EJ Jr., Denehy GE. A clinical study of nightguard vital bleaching. Quintessence Int 1993; 24(6): 379-84. 
27. Howard WR. Patient-applied tooth whiteners. J Am Dent Assoc 1992;123(2): 57-60.

28. Curtis JW, Dickinson GL, Downey MC, Russell CM, Haywood VB, Myers ML, Johnson MH. Assessing the effects of 10 percent carbamide peroxide on oral soft tissues. J Am Dent Assoc 1995;127(8): 1218-23.

29. Egger M, Smith GD. Meta-Analysis: Potentials and promise. BMJ 1997:315: 1371-4.

30. Greenhalgh T. Papers that summarize other papers (systematic reviews and meta-analyses) BMJ 1997;315: 672-5.

31. Feinstein AR, Horwitz RI. Problems in the "evidence" of "evidence-based medicine." Am J Med 1997;103: 529-35.

32. LeLorier J, Gregoire G, Benhaddad A, Lapierre J, Derderian F. Discrepancies between meta-analysis and subsequent large randomized controlled trials. New Engl J Med 1997;337: 536-42. Christensen GL. Bleaching Teeth: Report of a Survey, 1997. J Esth Dent 1998;10(1): 16-20.

\section{About the Authors}

\section{Richard Niederman, DMD MS}
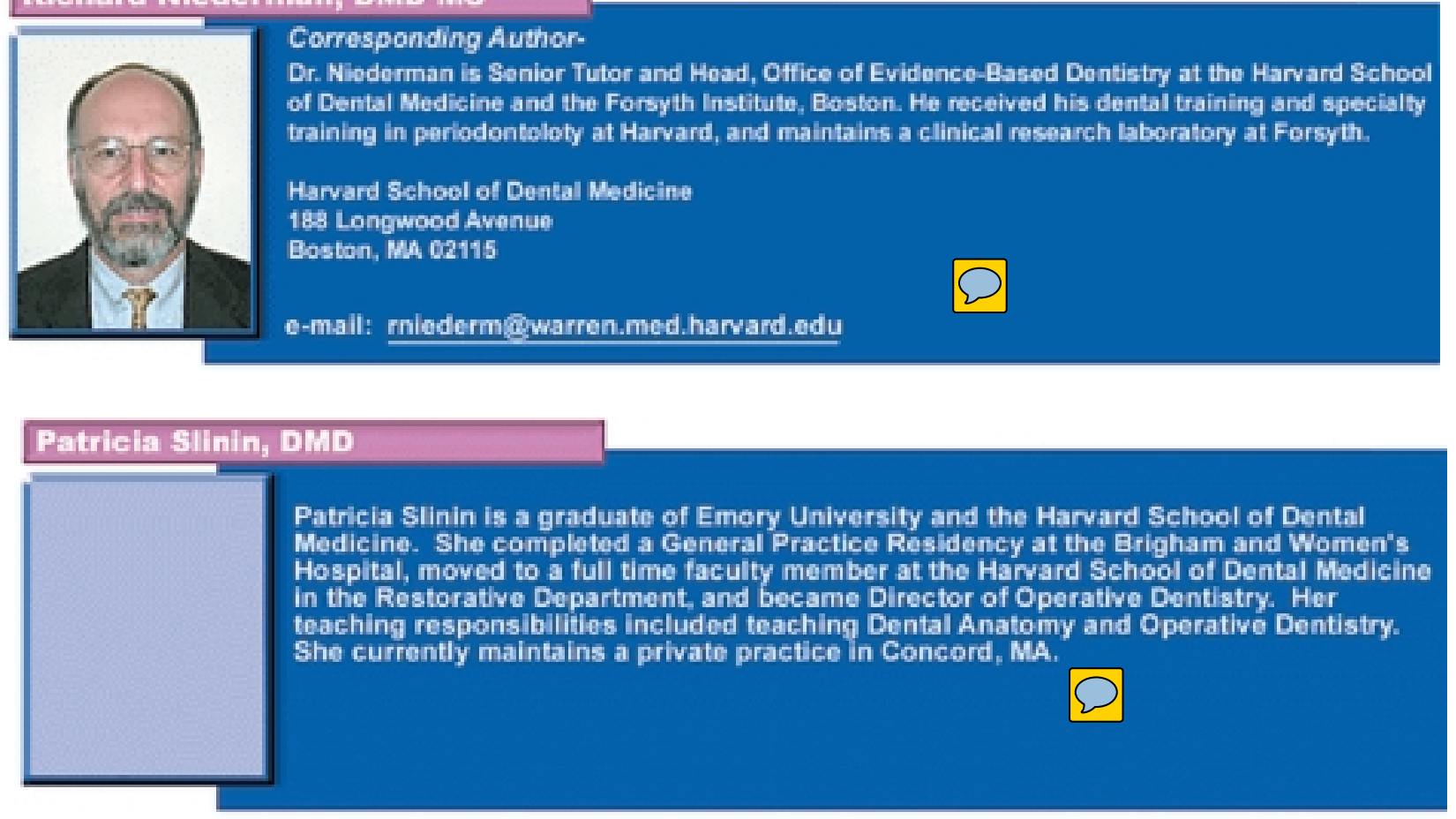

\section{Catherine Hayes, DMD, DMSe}

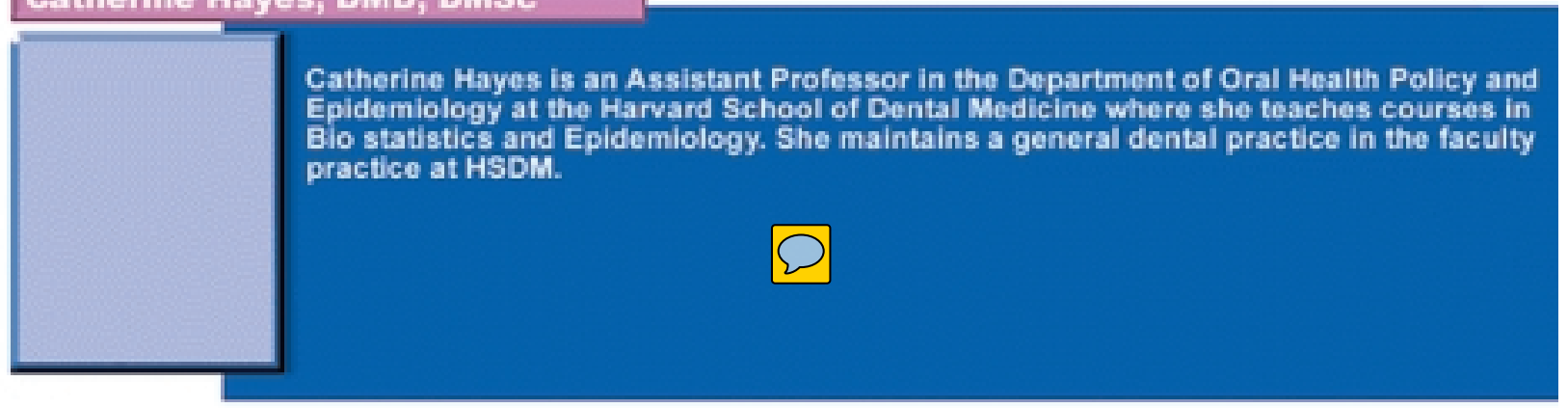




\section{Suzy Conway, MLS}

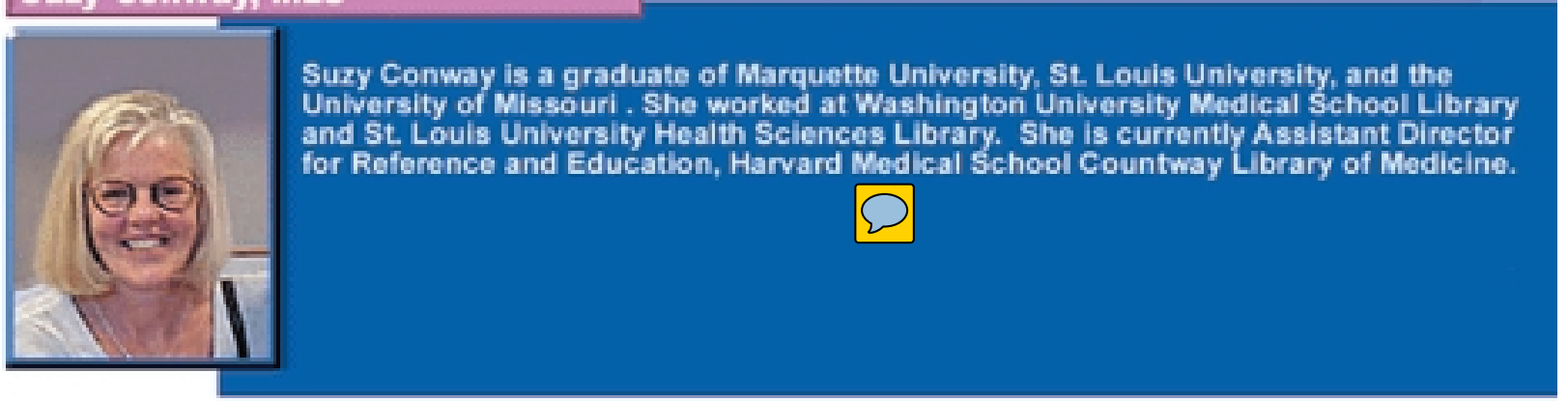

